\title{
Indices Indicating Early Renal Microvascular Disease in Diabetes
}

\author{
N. Futrakul ${ }^{*}, 1$ and P. Futrakul ${ }^{2}$ \\ ${ }^{I}$ Renal Microcirculation Research Group, Faculty of Medicine, Chulalongkorn University, Bangkok 10330, Thailand \\ ${ }^{2}$ Academy of Science, The Royal Institute of Thailand
}

\begin{abstract}
Renal microvascular disease is crucial to renal disease progression. Renal microvascular disease in late stage diabetic nephropathy is associated with defective angiogenesis and fails to respond to vasodilator treatment. Recognition of early renal microvascular disease is necessary, since in this stage, the vascular homeostasis is adequately functional and responsive to vasodilator treatment. Indices that can screen early renal microvascular disease include creatinine clearance or glomerular filtration rate, renal plasma flow or peritubular capillary flow and fractional excretion of magnesium (FE $\mathrm{Mg}$ ).
\end{abstract}

Keywords: Renal microvascular disease, Diabetes, Vascular homeostasis, Renal hemodynamics, FE Mg.

\section{INTRODUCTION}

Renal microvascular disease is a progressive entity that usually remains asymptomatic, and is recognized only when the disease is associated with advanced renal insufficiency. Accumulating evidence supports the correlation between renal microvascular rarefaction and the progression of tubulointerstitial disease [1-3]. Intrarenal hemodynamic study confirms the cause- and -effect relationship that the peritubular capillary flow reduction precedes the development of tubulointerstitial fibrosis in chronic kidney disease (CKD) indicating chronic renal ischemia is the crucial mechanism of renal disease progression [4]. Treatment to correct renal ischemia with vasodilators at early CKD or early diabetic nephropathy during normoalbuminuria can enhance renal perfusion as well as restore renal function; inasmuch as the vascular homeostasis is adequately functional in this early stage. In contrast, treatment with vasodilators at late stage (CKD stages 3-5) fails to correct renal ischemia, or restore renal function which is due to the altered vascular homeostasis and an impaired nitric oxide production observed in late CKD leading to the therapeutic resistance to vasodilators [5]. It is an unfortunate event, since treatment of CKD under common practice, is usually initiated at a rather late stage due to the late recognition of CKD secondary to the insensitiveness of the available diagnostic marker such as serum creatinine determination, as well as to the improper definition of CKD defined by the National Kidney Foundation. K/DOQI guidelines [6].

\section{INDICES INDICATING EARLY RENAL MI- CROVASCULAR DISEASE IN DIABETES}

In accordance with the preceding information, it is necessary to recognize early renal microvascular disease in order to implement the therapeutic intervention at an early stage under the environment favourable for angiogenesis and renal

\footnotetext{
*Address correspondence to this author at the Renal Microcirculation Research Group, Faculty of Medicine, Chulalongkorn University, Bangkok 10330, Thailand; Tel: 60813511214; Fax: 022584267;

E-mail: fmednft@yahoo.com
}

regeneration. Infact, early renal microvascular disease can be determined directly by intrarenal hemodynamic study. Determinations of renal plasma flow and peritubular capillary flow in a variety of patients associated with CKD or diabetes who had renal histopathologic study, have provided useful information regarding the pathogenesis of renal disease progression (Table 1). In this essence, renal plasma flow and peritubular capillary flow correlate inversely with the magnitude of tubulointerstitial fibrosis. It has been demonstrated that a CKD patient with a normal or mildly reduced renal perfusion does not develop tubulointerstitial fibrosis. A further reduction in renal perfusion to the level of thirty percent, induces a mild degree of tubulointerstitial fibrosis. A greater reduction in renal perfusion is associated with a higher magnitude of tubulointerstitial fibrosis [4-5]. In this regard, recognition of early renal microvascular disease can be reflected directly by intrarenal hemodynamic study which would detect the early reduction in renal plasma flow, or peritubular capillary flow, as well as by the histopathologic study of the kidney tissue which demonstrates the presence of renal microvascular rarefaction. In accordance with the correlation between tubulointerstitial fibrosis and renal microvascular disease, tubulointerstitial fibrosis can be a diagnostic marker reflecting renal microvascular disease. When the preceding diagnostic procedures are not performed or generally unavailable, they can be reflected indirectly by the determination of fractional excretion of magnesium (FE Mg). FE Mg has been demonstrated earlier to directly correlate with the magnitude of tubulointerstitial fibrosis in a variety of chronic kidney diseases [7]. In this essence, a mild elevation of FE $\mathrm{Mg}$ indicates the presence of a small magnitude of tubulointerstitial fibrosis, whereas the higher elevation of $\mathrm{FE} \mathrm{Mg}$ reflects the greater magnitude of tubulointerstitial firosis. In addition, $\mathrm{FE} \mathrm{Mg}$ has also been demonstrated to inversely correlate with the peritubular capillary flow reduction in type 2 diabetic nephropathy [8] and idiopathic nephrotic syndrome $[9,10]$.

In the absence of renal histopathologic study or intrarenal hemodynamic study, the determination of creatinine clearance can reflect the status of renal plasma flow or renal 
Table 1. Indices Indicating Early Renal Microvascular Disease and Early CKD

\begin{tabular}{|c|c|c|c|}
\hline \multicolumn{1}{|c|}{ Indices } & Early Renal Microvascular Disease and early CKD \\
\hline \hline 1. & Renal hemodynamic alteration & reflects & Renal microvascular disease and CKD \\
\hline 2. & Tubulointerstitial fibrosis & reflects & Tubulointerstitial fibrosis \\
\hline 3. & Fractional excretion of magnesium (FE Mg) & inversely reflects & Peritubular capillary flow \\
\hline 4. & FE Mg & reflects & Renal plasma flow \\
\hline 5. & Creatinine clearance or glomerular filtration rate & reflects & Renal microvascular disease \\
\hline 6. & Microalbuminuria & reflects & Renal microvascular disease \\
\hline 7. & $\begin{array}{c}\text { Altered vascular homeostasis (Defective angio- } \\
\text { genesis and elevated antiangiogenesis) plus renal } \\
\text { function impairment }\end{array}$ & & \\
\hline
\end{tabular}

\section{Glomerular Filtration Rate(GFR)-RPF}

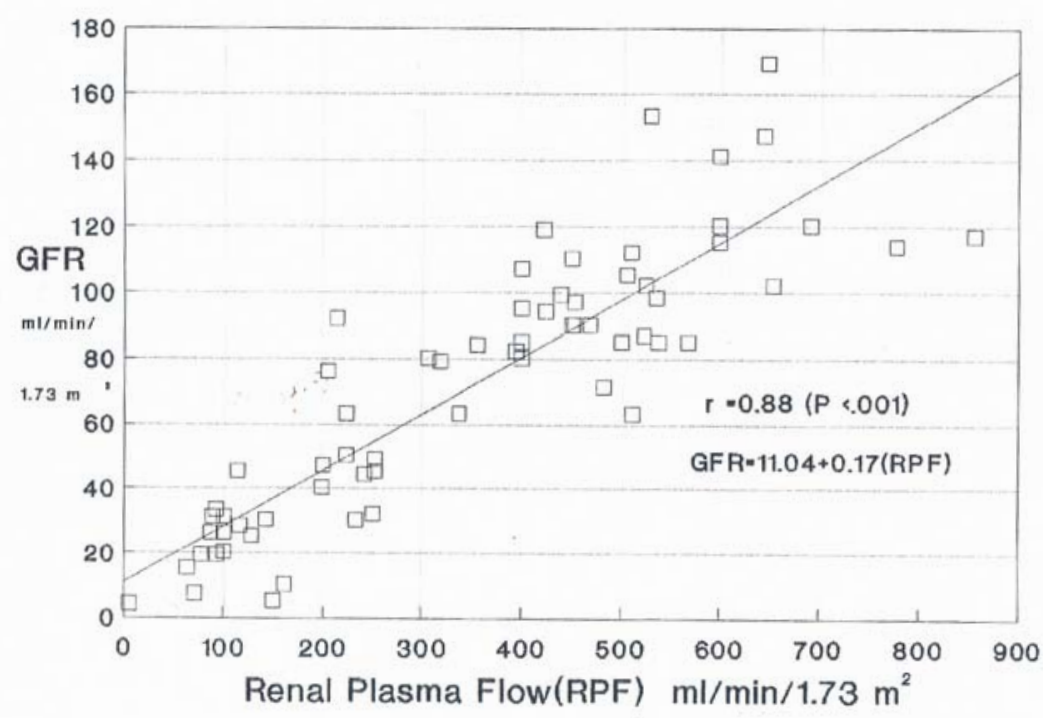

Fig. (1). Intrarenal hemodynamics demonstrates a direct correlation between renal plasma flow and GFR.

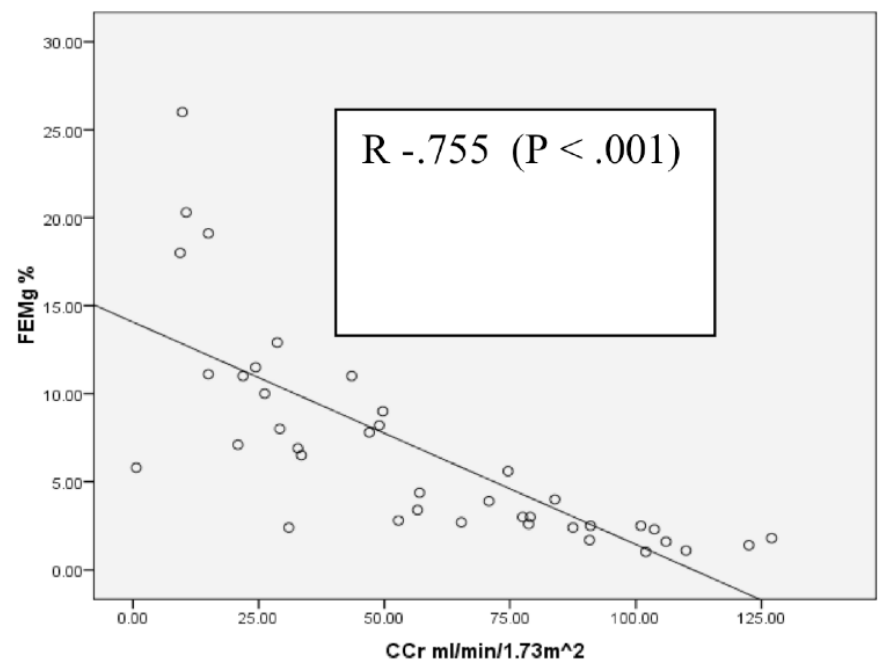

Fig. (2). Demonstrates a direct correlation between FE Mg and CCr. 
microvascular disease as well as the status of chronic kidney disease, since creatinine clearance or glomerular filtration rate correlates directly with renal plasma flow (Fig. 1) In addition to the above information, we have recently demonstrated that $\mathrm{FE} \mathrm{Mg}$ is also inversely correlated with the creatinine clearance (Fig. 2). Thus, under current practice, $\mathrm{FE} \mathrm{Mg}$ and creatinine clearance would be useful diagnostic indices to identify both early renal microvascular disease and early CKD.

Recently, microalbuminuria has been recognized as a biomarker reflecting renal microvascular disease [11,12]. Altered vascular homeostasis namely defective angiogenic factors such as vascular endothelial growth factor (VEGF), angiopoietin 1, VEGF receptor 1 and elevated antiangiogenic factors such as angiopoietin 2, VEGF receptor 2 reflects vascular disease. However, altered vascular homeostasis in conjunction with an impaired renal function such as an elevated serum creatinine would reflect renal microvascular disease [5,13-16]

\section{AN INNOVATIVE THERAPEUTIC STRATEGY TO RESTORE RENAL FUNCTION IN DIABETES}

Due to the present therapeutic failure in restoring the renal perfusion and function in late diabetic nephropathy, it is obvious that therapeutic strategy for diabetes should be implemented at early stage of renal microvascular disease or early CKD. Treatment at the early stage under which the vascular homeostasis is adequately functional, would assist the vascular response to vasodilator treatment with subsequent vasodilation in the renal microcirculation and thus correction of the renal ischemia. Indeed, vasodilator treatment with vasodilators at early CKD and early diabetic nephropathy during normoalbuminuria in recent studies could enhance renal perfusion, and restore renal function $[17,18]$.

\section{CONFLICT OF INTEREST}

None declared.

\section{ACKNOWLEDGEMENTS}

We are grateful to The National Research Council Fund of Thailand, Thailand Research Fund, and The Royal Institute of Thailand.

\section{REFERENCES}

[1] Bohle AC, Mackensen - Haen S, Wehrmann M. Significance of postglomerular capillaries in the pathogenesis of chronic renal failure. Kid Blood Pres Res 1996; 192: pp 191-5.
[2] Kang DH, Kanellis J, Hugo C, et al. Role of the microvascular endothelium in progressive renal disease. J Am Soc Nephro 2002; 13: 806-16.

[3] Nakagawa T, Kang DH, Ohashi R, et al. Tubulointerstitial disease: role of ischemia and microvascular disease. Curr Opin Nephrol Hypertens 2003; 12: 233-41.

[4] Futrakul N, Yenrudi S, Sensirivatana R, et al. Peritubular capillary flow determines tubulointerstitial disease in idiopathic nephrotic syndrome. Ren Fail 2000; 22: 329-35.

[5] Futrakul N, Futrakul P. Vascular homeostasis and angiogenesis determine therapeutic effectiveness in type 2 diabetes. Int $\mathbf{J}$ Vasc Med 2011; 10: 1-7.

[6] National Kidney Foundation. K/DOQI clinical practice guidelines for chronic kidney disease: evaluation, classification, and stratification, Am J Kidney Dis, 2002; 39 (Suppl 2), S1-266.

[7] Futrakul P, Yenrudi S, Futrakul N, et al. Tubular function and tubulointerstitial disease. Am J Kidney Dis 1999; 33: 886-91.

[8] Futrakul N, Butthep P. Early detection of endothelial injury and dysfunction in conjunction with the correction of hemodynamic maladjustment can effectively restore renal function in type 2 diabetic nephropathy. Clin Hemorheol Microcirc 2006; 34: 373-81.

[9] Futrakul N, Yenrudi S, Futrakul P, et al. Peritubular capillary flow and tubular function in idiopathic nephrotic syndrome. Nephron 2000; 85: 181-2.

[10] T. Deekajorndech, A biomarker for detecting early tubulointerstitial disease and ischemia in glomerulonephropathy. Ren Fail 2007; 29: 1013-8.

[11] Futrakul N, Sridama V, Futrakul P. Microalbuminuria - A biomarker of renal microvascular disease. Ren Fail 2009; 31: 140-3.

[12] Tomos C, Mironidou-Tzouveleki M. Vascular endothelial growth factor (VEGF) and its role in diabetic nephropathy. Epitheorese Klinikes Farmakologias kai Farmakokinetikes 2009; 27: 275-82.

[13] Cho WC, Yip TT, Chung WS, et al. Differential expression of proteins in kidney, eye, aorta, and serum of diabetic and nondiabetic rats. J Cell Biochem 2006; 39: 256-68.

[14] Sun H, Zheng JM, Chen S, et al. Enhanced expression of ANGPTL2 in the microvascular lesions of diabetic lomerulopathy. Nephron Exp Nephrol 2009; 105: 117-23.

[15] Cooper ME, Vranes D, Youssef S, et al. Increased renal expression of vascular endothelial growth factor (VEGF) and its receptor VEBFR2 in experimental diabetes. Diabetes 1999; 48: 2229-39.

[16] Nakagawa T, Kosuge T, Haneda M, et al. Abnormal angiogenesis in diabetic nephropathy. Diabetes 2009; 58: 1471-8.

[17] Ritt M, Ott C, Raff U, et al. Renal vascular endothelial function in hypertensive patients with type 2 diabetes mellitus. Am J Kidney Dis 2009: 53; 281-9.

[18] Futrakul N, Kulapatana O, Futrakul P. et al. Enhanced peritubular capillary flow and renal function can be accomplished in normoaluminuric type 2 diabetic nephropathy. Ren Fail 2011; 33: 3125.

(C) Futrakul and Futrakul; Licensee Bentham Open.

This is an open access article licensed under the terms of the Creative Commons Attribution Non-Commercial License (http://creativecommons.org/licenses/by-nc/3.0/) which permits unrestricted, non-commercial use, distribution and reproduction in any medium, provided the work is properly cited. 